\title{
Research and Development of Fully Green Composites Reinforced with Natural Fibers"
}

\author{
Koichi GODA $^{* *}$ and Yong CAO ${ }^{* * * * *}$ \\ **Department of Mechanical Engineering, Yamaguchi University, \\ 16-1 Tokiwadai 2-chome, Ube, Yamaguchi 755-8611, Japan \\ *** JSPS Postdoctoral Fellowship for Foreign Researchers \\ E-mail: cao@yamaguchi-u.ac.jp \\ goda@yamaguchi-u.ac.jp
}

\begin{abstract}
With looming environmental problems and the global energy crisis, fully green composites of natural fibers and biodegradable resin have increasingly attracted research interest because of their advantages of low cost, renewable resource usage, and biodegradability. Recent studies and developments are reviewed in this article, including short fiber green composites, unidirectional green composites, textile and cross-ply green composites, and technologies for improvement of natural fibers and these composites. Fabrication methods, molding conditions, and mechanical properties of the composites are discussed in detail. A key approach of natural fiber toughness improvement by chemical treatment along with its effect on the composites is reported as an excellent example. Finally, future development trends related to fully green composites are predicted.
\end{abstract}

Key words: Green Composites, Biodegradable Composites, Natural Fibers, Plant-Based Fibers, Biodegradable Resin, Biomass, Mechanical Properties

\section{Introduction}

Fiber-reinforced plastic composites, usually made of glass, carbon and aramid fiber reinforced with epoxy and unsaturated polyester, have played a dominant role during the last several decades in various applications because of their high mechanical strength and modulus. However, usage and disposal of these materials, especially glass-fiber-reinforced plastic (GFRP), have been becoming critical because of their non-biodegradability in light of increasing environmental consciousness and demands of legislative authorities related to their recycling. Recently, completely biodegradable composites reinforced with natural fibers, which are called fully green composites, have attracted much interest to solve these problems.

Natural fibers such as jute, flax, ramie, and sisal ${ }^{(1)-(10)}$ are usually used as reinforcement in green composites; biodegradable resins made of derivatives from cellulose, starch, lactic acid, etc. are applied as the matrix material. The biodegradable property of both components makes them easily disposed of or composted at the ends of their useful lives. Advantages of natural fibers over other reinforcing materials like glass fiber are their low cost, low density, acceptable specific strength properties, enhanced energy recovery, and biodegradability. Although these green composites are not as strong as the traditional GFRP now, the moderate mechanical properties are suitable for applications in non-durable consumer products and packing materials, etc. Moreover, the hollow tubular structure of natural fibers reduces their bulk density. Therefore, composites made from them are expected to be lightweight. 
However, the main drawback of natural fibers is that their hydrophilic property lowers compatibility with the hydrophobic polymeric matrix during composite fabrications. As a result, the poor fiber-matrix adhesion engenders low mechanical properties. The other disadvantage is the low processing temperatures that must be used because of the possibility of fiber thermal degradation, which might affect composite properties. It is necessary to improve mechanical and other properties in natural fibers before the fabrication of composites. In addition, the fact that the high cost of biodegradable resins at present might limit their application for green composites should not be ignored, but those costs are expected to fall in the future.

In this article, we shall review recent studies and developments related to fully green composites. Various green composites, including short-fiber green composites, unidirectional green composite, textile and cross-ply green composites, and technologies for improved use of natural fibers as well as these composites are discussed in terms of their fabrication methods, molding conditions and mechanical properties. To improve natural fibers' and green composites' toughness, an effective method of alkali treatment with load application to fibers is reported in detail, in addition to its effect on the composites. Finally, future development trends related to fully green composites are predicted.

\section{Background of concept of fully green composites}

With growing production and mass volume use, the disposal of non-biodegradable composites after their intended useful life has become an important and expensive issue. Most of these composites are eventually incinerated and landfilled. However, incineration is expensive and wasteful. The released gases might also bring new pollution. Because landfill areas are decreasing and new environmental problems occur together with these traditional means of disposal, people must be urged to find a new effective means of disposal. In addition, since composites combine two dissimilar materials, they can not be easily recycled and reused, although some efforts have been made to do so.

To reduce the cost of composite fabrication and to make them lightweight, wood flour and natural fibers were used as reinforcement or filler in early composites. In the 1980s, composites made of cellulosic fibers combined with thermoset resin began ${ }^{(11)(12)}$; then, in the 1990s, thermoplastic composites reinforced with wood flour were reported and extended to high-strength natural-fiber-reinforced thermoplastic composites (13)(14). Chemical compositions and mechanical properties of some natural fibers are presented in Tables 1 and $2^{(15)-(18)}$. The mechanical properties of natural fibers depend mainly on the amount of cellulose as well as the microfibrillar angle. Among the bast fibers, ramie and hemp have higher tensile strength and modulus because of their high cellulose content and low microfibrillar angle. Although the tensile strength and modulus of natural fibers are not as high as those for glass fiber, their specific tensile strength and modulus are close to the values of glass fiber, indicating the possibility that natural fibers can replace glass fiber as reinforcement in composites.

Table 1 Chemical composition and structure parameters of some natural fibers

\begin{tabular}{lccccccc}
\hline Fiber & $\begin{array}{c}\text { Cellulose } \\
/ \mathrm{wt} \%\end{array}$ & $\begin{array}{c}\text { Hemicellulose } \\
/ \mathrm{wt} \%\end{array}$ & $\begin{array}{c}\text { Lignin } \\
/ \mathrm{wt} \%\end{array}$ & $\begin{array}{c}\text { Pectin } \\
/ \mathrm{wt} \%\end{array}$ & $\begin{array}{l}\text { Wax } \\
/ \mathrm{wt} \%\end{array}$ & $\begin{array}{l}\text { Microfibrillar/ } \\
\text { Spiral angle / Deg. }\end{array}$ & $\begin{array}{c}\text { Moisture content } \\
\text { / wt } \%\end{array}$ \\
\hline Flax & 71 & 2.2 & $18.6-20.6$ & 2.3 & 1.7 & 10 & 10 \\
Jute & $61-71.5$ & $12-13$ & $13.6-20.4$ & 0.2 & 0.5 & 8.0 & 12.6 \\
Ramie & $68.6-76.2$ & $0.6-0.7$ & $13.1-16.7$ & 1.9 & 0.3 & 7.5 & 8 \\
Hemp & $70.2-74.4$ & $3.7-5.7$ & $17.9-22.4$ & 0.9 & 0.8 & 6.2 & 10.8 \\
Kenaf & $31-39$ & $15-19$ & 21.5 & - & - & - & 12 \\
Sisal & $67-78$ & $8-11$ & $10-14.2$ & 10 & 2 & 20 & 11 \\
Henequen & 77.6 & 13.1 & $4-8$ & - & - & - & - \\
\hline
\end{tabular}


Table 2 Mechanical properties of some natural fibers

\begin{tabular}{lcccccc}
\hline \multirow{2}{*}{ Fiber } & $\begin{array}{c}\text { Specific } \\
\text { gravity }\end{array}$ & $\begin{array}{c}\text { Average diameter } \\
\text { /mm }\end{array}$ & $\begin{array}{c}\text { Tensile strength } \\
\text { /MPa }\end{array}$ & Specific strength & $\begin{array}{c}\text { Young's modulus } \\
\text { /GPa }\end{array}$ & $\begin{array}{c}\text { Specific } \\
\text { modulus }\end{array}$ \\
\hline Bamboo & 0.80 & 0.187 & 465 & 581.3 & $18.0-55.0$ & $22.5-68.8$ \\
Jute & 1.30 & 0.01 & 394 & 303.1 & 55.0 & 42.3 \\
Manila hemp & 1.30 & 0.20 & 792 & 609.2 & 26.6 & 20.5 \\
Ramie & 1.16 & 0.034 & 560 & 482.8 & 24.5 & 21.1 \\
Kenaf & 1.04 & 0.078 & 448 & 430.8 & 24.6 & 23.7 \\
E-glass & 2.56 & $0.008-0.014$ & $1400-2500$ & $546.9-976.6$ & $55.8-99.6$ & $21.8-38.9$ \\
\hline
\end{tabular}

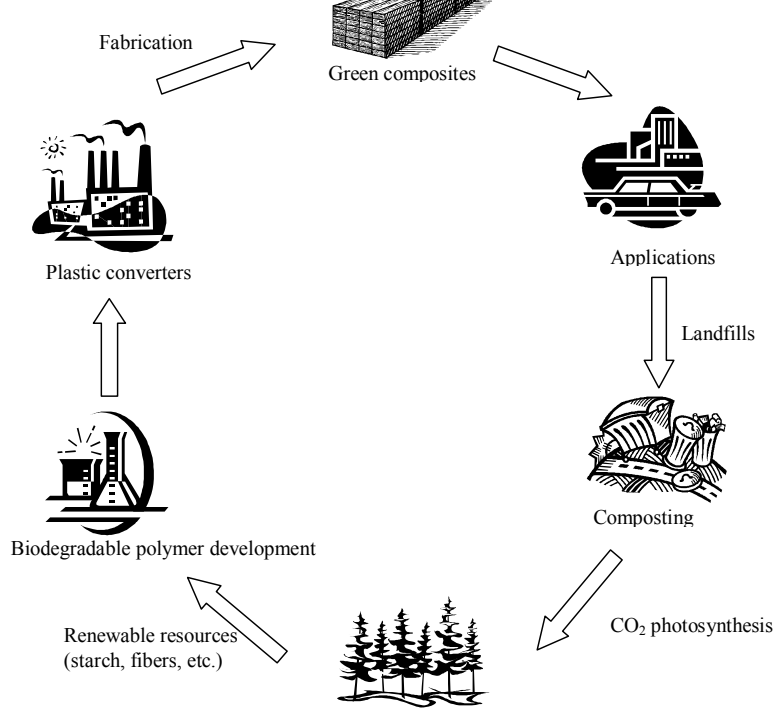

Fig. 1 Life cycle of green composites

The most important feature of green composites is their full biodegradability. Figure 1 shows that, at the end of their intended life, these composites can be completely resolved into water and carbon dioxide through degradation by microorganisms after burial in the soil, or incinerated without emissions of toxic gases. Consequently, green composites are a renewable, eco-friendly, and biodegradable material. A study of the fabrication of green composites was initially reported by Herrmann et al. ${ }^{(19)}$. Composites made from ramie and hemp fibers and a blend of starch and polyvinylalcohol (PVA) resin were prepared and named as a bio-composite. The phrase green composite first appeared in Netravali's paper (7)(20). They developed a coir-fiber-reinforced Polyhydroxybutyrate-co-volerate (PHBV) resin composite and investigated its mechanical properties. Researchers in Europe have also called them biodegradable composites instead of green composites until now.

\section{Fabrication and mechanical properties of fully green composites}

\subsection{Short-fiber green composites}

Injection molding is well known to be used usually for molding short-fiber-reinforced composites in mass production because of its short cycle time and high productivity. With the purpose of developing eco-friendly electronic products, $\mathrm{Iji}^{(21)}$ prepared green composites made from kenaf fibers and polylactic acid (PLA) resin using injection molding. Fibers of less than $5 \mathrm{~mm}$ length were used. Compared with the flexural strength of $132 \mathrm{MPa}$ and the flexural modulus of 4.5 GPa of PLA only, it was noticed that the flexural strength of these composites decreased, whereas the flexural modulus of elasticity increased with increasing 
fiber volume fraction. When the fiber volume fraction was $20 \%$, the flexural strength and the flexural modulus of elasticity of the composite were, respectively, $93 \mathrm{MPa}$ and $7.6 \mathrm{GPa}$. Comparable values of short glass-fiber-reinforced acrylonitrile butadiene styrene (ABS) resin composites at the same volume fraction were, respectively, $110 \mathrm{MPa}$ and $7.3 \mathrm{GPa}{ }^{(22)}$, which indicates the modulus of elasticity of the kenaf-fiber-reinforced green composite was comparable to that of glass fiber composites. Furthermore, the results of an Izod impact test showed that the impact strength improved from $4.4 \mathrm{~kJ} / \mathrm{m}^{2}$ to $7.8 \mathrm{~kJ} / \mathrm{m}^{2}$ when a plasticizer was added to PLA resin prior to fabrication of the composites.

Shibata et al. ${ }^{(4)(5)}$ also developed green composites reinforced with abaca fibers using injection molding. Abaca fibers were cut to 3-7 mm length with average diameter of $0.2 \mathrm{~mm}$. Three kinds of biodegradable resin, PHBV (Biophane; Gunze Co.), PBS (Polybutadienestyrene, Bionolle 1020; Showa Highploymer Co. Ltd.) and PLA (Lacty9030; Shimadzu Co. Ltd.), were used in fabrication. The different mass fractions fibers and resins were compounded and kneaded using a double arm mixer at $140^{\circ} \mathrm{C}$ (PHVB and PBS) and $190^{\circ} \mathrm{C}$ (PLA) for $5 \mathrm{~min}$. Then the resulting compound was pelletized through immersion in liquid nitrogen. Finally, the pellets were molded to composites under different injection-molding conditions. Maximum tensile properties of abaca/PHVB composites were shown at fiber length of $5 \mathrm{~mm}$. Compared with the flexural strengths, $27 \mathrm{MPa}$ and $43 \mathrm{MPa}$, of PHBV and PBS; the flexural moduli, 0.9 GPa and 0.75 GPa, of PHBV and PBS, the flexural properties of these composites increased with increasing fiber mass fraction. After surface treatment of abaca with butyric anhydride and pyridine, the flexural strength and modulus in the composites of 20 mass \% were increased respectively from $27 \mathrm{MPa}$ to $40 \mathrm{MPa}$, and from 0.9 $\mathrm{GPa}$ to $2.2 \mathrm{GPa}$. These values resemble those of glass/PHVB composites. Similar results were obtained for abaca/PBS and abaca/PLA composites. In addition, the results of soil burial tests showed that the composites reinforced with abaca fibers had a higher weight loss than the neat resin.

Among natural fibers, bagasse has attracted much interest. Bagasse is the waste fiber of sugarcane after juice extraction. Aiming at an advanced effective application of bagasse, Cao et al. (23)-(26) fabricated bagasse-fiber-reinforced biodegradable resin composites using compression molding. The effect of alkali treatment of bagasse fibers on mechanical properties was studied, the effects of fiber volume fraction and length on flexural properties were investigated, and the flexural modulus was predicted based on the modified COX shear-lag model. The bagasse fibers before and after different alkali treatments were used as reinforcement; a cornstarch-base biodegradable resin, CP300, was used as the matrix. The composites reinforced with $1 \%$ alkali-solution-treated fibers showed maximum improvement in mechanical properties because of fibrillation and surface modification of the treated fibers. Approximately 13\% improvement in tensile strength, $14 \%$ in flexural strength, and $30 \%$ in impact strength were obtained. Subsequently, SEM micrographs showed that compression of the cellulose structure of bagasse fiber after preparation might have caused the improvement in the mechanical properties of fibers. The flexural modulus also increased with the increase of fiber volume fraction up to $66 \%$, yet decreased over $66 \%$ because of insufficient resin. Figure 2 shows that the calculated flexural modulus by modified COX model, incorporating the fiber compression ratio 3.4, agreed well with the experimental results. Moreover, a decrease of flexural modulus was found below the fiber length of 3.2 $\mathrm{mm}$ because of the decreased aspect ratio.

Bodros et al., using a film stacking method ${ }^{(27)}$, also developed green composites that were reinforced with randomly scattered flax fibers. Flax fibers were cut to $10 \mathrm{~mm}$ length and fiber mats were prepared using a paper mill technique. Green composites were molded from a stack of biopolymer films that were interleaved with flax fiber mats. The results showed that the fiber volume fraction has a significant effect on the tensile properties of the green composites, as can be expected. Young's modulus of flax short-fiber-reinforced PLLA 


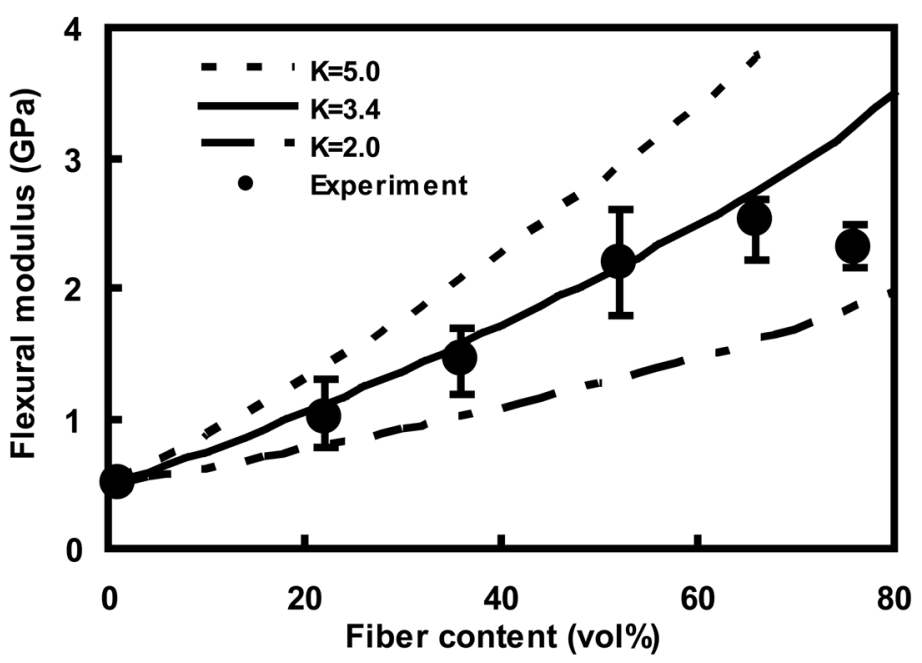

Fig. 2 Variation of the flexural modulus with varying volume fraction of bagasse fiber ${ }^{\text {(26) }}$ (K: fiber compression ratio)

(Poly-L-lactic, BiomerL9000) composites increases from 7.5 GPa to $9.5 \mathrm{GPa}$ when the fiber volume fraction increased from $20 \%$ to $30 \%$; moreover, the tensile strength of these composites also increased from $80 \mathrm{MPa}$ to $100 \mathrm{MPa}$. Other PLA (4O42D; Cargill-Dow)-based composites reinforced with the same flax fiber mats were fabricated and were compared with to the PLLA-based composites. In the case of PLA-based composites, the tensile properties were less than the PLLA-based ones. Yet as to MAPP (PP7650 blended with 5\% PP-g-MA; Atofina Chemicals Inc.)-based composites, the tensile strength and Young's modulus were $72 \mathrm{MPa}$ and $5.5 \mathrm{GPa}$, respectively, which were inferior to the composites fabricated using PLLA. Results indicate that the specific Young's modulus of PLA-based composites is almost the same as that of the glass-fiber-reinforced polyester composites. On the other hand, the specific strength of the flax-fiber-reinforced green composites is slightly lower than that of the glass fiber composites. Therefore, it might be concluded that green composites reinforced with plant-based natural fibers are comparable to glass fiber composites in terms of stiffness, but have somewhat lower strength.

\subsection{Unidirectional green composites}

Compared to short-fiber-reinforced composites, unidirectional fully green composites present higher strength properties along with the fiber axis direction, similar to general composite materials, and can be predicted using the rule of mixtures in composites.

Continuous natural fibers and yarns have been used to prepare unidirectional fully green composites in many studies. In composites reinforced with natural fibers of high fiber content from $60 \mathrm{vol} \%$ to $70 \mathrm{vol} \%$, however, it has been found that neighboring fibers contact with each other without resin because of poor resin permeation in the fibers. Consequently, internal defects of composites have occurred and the mechanical properties decreased. A pre-forming method was developed by Takagi et al. ${ }^{(28)-(30)}$ to solve the problem. In their study, Manila hemp fibers were dipped into an emulsion-type biodegradable resin in which the micro-resin particles are dispersed in water; then the resulting fibers, coated with a thin particles layer, were obtained after drying. Fully green composites were fabricated by simple compression molding under appropriate conditions. The composites showed excellent mechanical properties at fiber content of $75 \%$ by weight, and high tensile strength and high modulus was of $307 \mathrm{MPa}$ and $35 \mathrm{GPa}$, respectively, in the direction of the fiber axis. Such high strength and stiffness of green composites were also reported by Goda et al. ${ }^{(31)}$, when curaua-fiber-reinforced composites were molded using a similar technique. Furthermore, Okuno et al. ${ }^{(32)}$ investigated PVA-resin-based green composites reinforced using 
unidirectional bamboo fibers. The maximum mass fraction in this case was close to $85 \%$. High tensile strength and high Young's modulus were presented as expected; these values can be estimated from the rule of mixture. In the studies described above, SEM microphotographs displayed a good fiber/matrix adhesion.

Not only natural fibers, but also yarns are applicable for preparation of green composites. Goda et al. (33)(34) fabricated ramie-yarn-reinforced cornstarch-base biodegradable resin composites through compression molding. In this case, mechanical properties showed maximum values at optimum pressure of 13.1 MPa. After alkali treatment of the yarns, the tensile strength did not vary, although the toughness increased markedly. Khondker et al. ${ }^{(35)}$ also developed unidirectional PLA green composites reinforced with jute yarns. In their study, a unique intermediate material called 'micro-braid yarn', consisting of core jute fibers in braided PLA fibers, was prepared using a tubular braiding machine. Then the micro-braid yarns were wound around a metallic frame in a parallel configuration. They were then compression molded to produce composite specimens in a die. The results showed flexural strength of $78 \mathrm{MPa}$ and Young's modulus of $8.5 \mathrm{GPa}$ for composites at $38 \%$ fiber volume fraction.

\subsection{Textile and cross-ply green composites}

Different from the short-fiber and unidirectional green composite, textile composites consist of polymer matrix combined with textile reinforcement, which are quite useful for some applications in light of their simple processing and unique 3-D mechanical properties. Typical applications of these composites range from structural parts for general cars to high-performance aerospace components. Thus, textile structure and technique are expected to develop the performance of green composites.

Chabba and Netravali ${ }^{(36)}$ used flax fabrics and modified soy protein concentrate resin to form green composites. The fabric-reinforced composites showed Young's modulus values of around $1 \mathrm{GPa}$ in the transverse direction and $0.5 \mathrm{GPa}$ in the longitudinal direction. The strength in the two directions was between 50-55 MPa. The results suggest that the textile green composites might be useful in many applications for packing and panels for indoor applications.

A cross-ply structure in composites can bear external loads applied for various directions. Therefore, Takagi et al. ${ }^{(37)(38)}$ developed cross-ply laminate green composites reinforced by compression molding using Manila hemp fiber. The hemp fiber bundles were woven as a sheet as reinforcement and cornstarch-base biodegradable resin was used as the matrix. Both tensile and flexural strengths increased with increasing fiber contents, yet the tensile strength remained at constant values with fiber contents over $50 \%$ by weight. Maximum tensile and flexural strength in $0^{\circ}$ ply laminate green composites were, respectively, $104 \mathrm{MPa}$ and $153 \mathrm{MPa}$. In addition, results showed different influences on mechanical properties when hemp fiber and cotton yarns were applied as weft during weaving. Figure 3 shows the different influences on tensile strength of composites with different wefts. Using the cotton weft, tensile strength of these composites showed higher strength values in $0^{\circ}$ and cross plies. It is considered that the warps tend to be straighter (with less crimp) along the tensile (longitudinal) direction as a result of the flexibility of the cotton yarns. On the other hand, the composites with hemp weft decrease in strength, which might be attributable to the result that the warps in this case tend to cause larger crimp and then engender the wavy shape caused by a higher stiffness of the hemp fibers. The tensile strength values of $379 \mathrm{MPa}$ in unidirectional composites and $188 \mathrm{MPa}$ in cross-ply composites using the cotton weft are considered higher in the field of all plant-based natural fiber composites, including green composites.

Investigation of deformation behaviors and the plasticity in warp and weft directions of textile green composites using ramie woven fabrics were reported by Goda et al. ${ }^{(39)-(41)}$. Two 


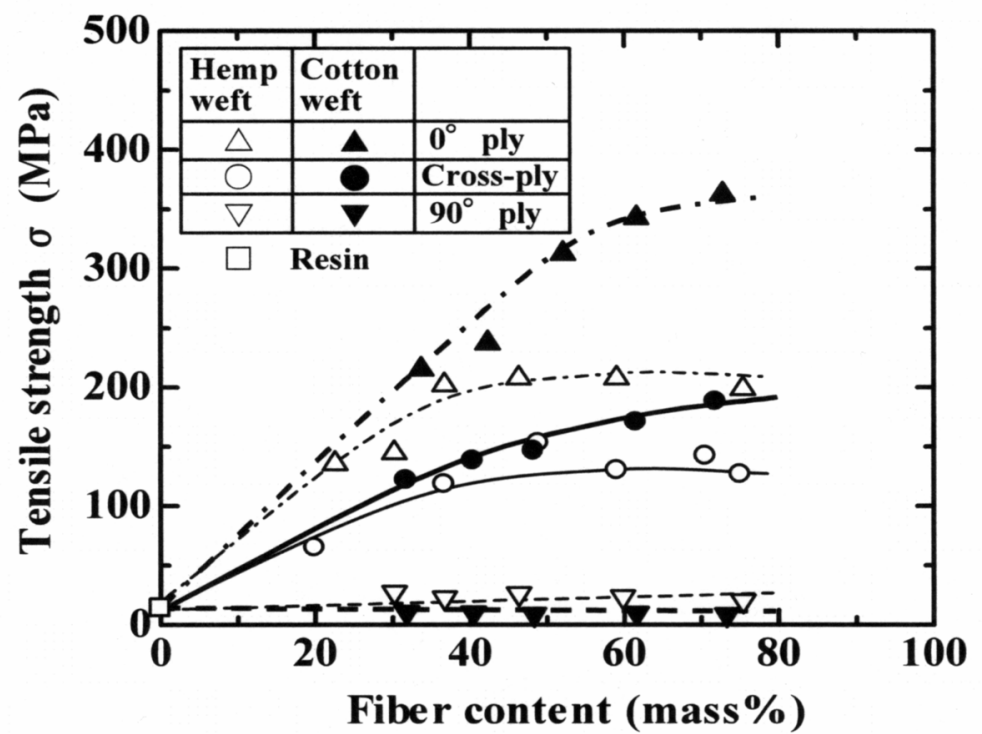

Fig. 3 Effect of fiber contents on the tensile strength of the cross-ply green composites ${ }^{(38)}$

different fabrics were applied as reinforcement to prepare the composites and compare the plasticity behavior: automatically woven fabrics using non-twisted ramie yarns and manually woven fabrics using five-twist plied yarns. The composites reinforced with the former woven fabrics showed a greater plastic deformation than those reinforced with the latter. Alkali-treated fabric composites exhibited increased plasticity in the fiber direction, and the fracture strain of $3.6 \%$ was higher than the untreated. The experimental result also indicated that a suitable lamination structure can bring quasi-isotropic plasticity in the composites. The creation of plasticity in textile green composites can improve mechanical properties.

Nishino et al. ${ }^{(42)}$ developed kenaf-fiber-sheet reinforced PLLA composites. Kenaf sheets were dried at $120^{\circ} \mathrm{C}$ in advance and immersed into PLLA dioxane solution $10 \mathrm{wt} \%$ under vacuum. The tensile strength and Young' modulus of green composites were, respectively, $62 \mathrm{MPa}$ and $6.3 \mathrm{GPa}$. The SEM microphotographs of the kenaf sheet showed that the fibers were oriented preferentially in the vertical direction; consequently, the composites had some anisotropy in mechanical properties. On the contrary, this anisotropy was weakened due to the lamination of $\left[0^{\circ}, 90^{\circ}, 45^{\circ}\right]_{\text {sym }}$ using the unidirectional sheets, which can bring an quasi-isotropy for mechanical properties of the composites.

\subsection{Improvement in mechanical properties of green composites}

As described earlier, green composites present lower mechanical properties than GFRP because of the low mechanical properties in natural fiber. In addition, their properties might be influenced by hydrophilic and water absorption properties and thermal degradation in fibers, poor fiber/matrix adhesion, and so on. The quality of the fiber/matrix interface is significant for application of natural fibers as reinforcement fibers for composites. Therefore, physical and chemical methods are useful to optimize this interface and therefore enhance mechanical properties of composites. Physical and mechanical methods, such as stretching, heat treatment, plasma treatment and electric discharge, do not change the chemical composition of the fibers, but can change structural and surface properties of the fiber and thereby influence the mechanical properties. Strongly polarized natural fibers are inherently incompatible with hydrophobic resins. Therefore, chemical methods, such as a change of fiber surface tension, chemical coupling, acetylation, and alkali treatment, are considered to improve fiber/matrix adhesion by coupling agents in composites.

In this section, an example of improvement of the toughness in green composites was presented. Alkali treatment of natural fibers for improving their brittle properties and the composites toughness were discussed. Regarding improvement in toughness of the 
reinforcement, Goda et al. ${ }^{(43)}$ developed a new chemical treatment with load application to ramie fiber. The ramie fibers were alkali treated using $15 \mathrm{wt} \% \mathrm{NaOH}$ solution with applied load $0.098 \mathrm{~N}$ for $2 \mathrm{~h}$. Untreated and alkali-treated single ramie fibers were tested to compare their tensile properties. The results showed that the alkali-treated fibers had significantly higher fracture strain from $6 \%$ to $8 \%$, twice to three times higher than that of the untreated fibers. Notwithstanding, no significant reduction was found in tensile strength. Such large improvement in fracture strain without strength loss translates directly to improved toughness. As is well known, alkali treatment by high concentration $\mathrm{NaOH}$ solution, termed the mercerization technique, changes the crystal structure of cellulose $\mathrm{I}$ in natural fibers to cellulose II ${ }^{(44)}$. The increase of cellulose II often accompanies a marked decrease in the strength of natural fibers. However, the $\mathrm{NaOH}$ solution concentration used in this study was considered to be too low to change all cellulose I to cellulose II, and therefore agreed with the result of slight tensile strength loss. In addition, angles of the microfibrils, which are spirally positioned in the secondary wall of the fiber cell, might decrease when the load was applied to the fibers during alkali treatment, enhancing their strength. Such improvement in the fracture strain of natural fibers was also observed by Bledzki et al. ${ }^{(45)}$ for hemp fibers.

Efforts at producing a toughened green composite were performed by Uno et al. ${ }^{(46)}$. The composites were reinforced with alkali-treated ramie plied yarns (No.16, five twists; Tosco Co.). The ramie yarns were alkali-treated without load application under the same conditions as those described in the paper mentioned previously ${ }^{(43)}$. The green composites with fiber volume fractions of $60-70 \%$ were fabricated using compression molding. The tensile strength and Young's modulus of the treated yarn composites decreased to $284 \mathrm{MPa}$ and 16.3 $\mathrm{GPa}$, respectively, compared to $304 \mathrm{MPa}$ and $21.7 \mathrm{GPa}$ of the untreated yarn composites, whereas the fracture strains of the alkali treated composites increased dramatically from $2.45 \%$ to $5.69 \%$. Such a small decrease in strength and a great increase in fracture strain indicated that this green composite had remarkably higher toughness. The result of a drop-weight impact test showed that the absorbed energy of the cross-ply laminate composites reinforced with alkali treated ramie yarn was $12.7 \mathrm{~J}$, twice higher than the value obtained from that of the untreated yarn composite $(5.71 \mathrm{~J})$. In addition, textile green composites laminated with different layers, which are made from alkali-treated ramie plain woven fabrics, were prepared and impact tests were performed. The absorbed energy of textile green composites was much higher than those of GFRP. That is to say, the absorbed energies of two- and three-layer textile green composites were $13.2 \mathrm{~J}$ and $26.4 \mathrm{~J}$, but those of GFRP reinforced with two and three glass-roving-mats were $9.04 \mathrm{~J}$ and $15.1 \mathrm{~J}$. These results clarified that alkali treatment applied to ramie yarns can indeed improve the impact resistance of green composites.

\section{Development trends of fully green composites}

Increasingly strict environmental regulations, demands for renewable and recyclable materials, the looming energy crisis, the shortage of landfill space, and public concerns about emissions during incineration of traditional GFRP have spurred efforts to develop biodegradable composites. Governments in Europe and Japan have encouraged the research and development of fully green composites. Increasingly, companies have tried to use green composites in their products as well. As a prime example, Toyota Motor Co. has used green composites made from kenaf fibers to replace plastic-based and metal-based automotive components. Intensive co-operation among industries, research institutes, and governments is essential to advance the development of green composites.

It is expected that the future green composites will show comparable or even superior mechanical properties to GFRP, exhibit structural and functional stability during storage and use, and yet allow easy microbial and environmental degradation after disposal, without imparting an adverse environmental burden. Future development trends in fully green 
composites include, first, the formation of a green composite at low cost, which can also win public and political acceptance. Along with increasing development of cheaper and newer green resins, in addition to the market demand and mass production of green composites, the cost will most probably decrease. On the other hand, current and future studies should specifically examine fabrication of new multifarious green composites composed of different resins as well as fibers of various forms including yarns, fabrics and nonwovens, etc. Aimed at future mass application and production, optimum data of processing and investigation of mechanical properties in existing green composites should be summarized to a data base. Meanwhile, because of the very complex structure of natural fibers, more data related to properties of fibers and composites are also required to establish confidence for their future applications.

Fully green composites with outstanding physical and mechanical properties are not a dream today. Proper molding techniques and fiber treatments can provide composites with better properties to match various requirements. Techniques of fiber modification including alkali treatment, cross-linking, coupling agents, etc. can improve the fiber properties and fiber/matrix adhesion. An additional method is to add nanoclay and micro-fibrillated and nano-fibrillated cellulose to green composites, which can increase the functional groups on the surface of fibers and resins, thereby enhancing the mechanical properties of composites. This method also improves the thermal properties and provides moisture to some resins in some cases. In the face of the challenge in replacing the conventional GFRP, some approaches have been useful for designing superior strength composites: efficient natural fiber treatment, matrix resin modification, and selection of optimum processing conditions. For example, coating the fibers using plasma polymerization and other techniques are considered to decrease their moisture sensitivity to maintain their mechanical properties. Otherwise, the accelerating development of high-strength fibers based on cellulose or proteins will support fabrication of advanced green composites in the future. The most notable research has been carried out at Nexia Biotechnologies, where spider silk genes were transplanted in goats ${ }^{(47)}$. The spider silk protein is then expressed in the goat milk, which is purified and spun into fibers.

Finally, although fully green composites could be used in cars today, newer and even more promising potential applications in construction, railways, aircraft, sports, etc. should be studied for the future. Studies of biodegradation behaviors at the end of use life and reliability during the intended life also should be carried out immediately. A comprehensive evaluation system for fully green composites must be established.

\section{References}

(1) Mohanty, A.K., Khan, M.A. and Hinrichsen, G., Influence of chemical surface modification on the properties of biodegradable jute fabrics-polyester amide composite, Composites: Part A, Vol. 31, (2000), pp.143-150.

(2) Mohanty, A.K., Khan, M.A. and Hinrichsen, G., Surface modification of jute and its influence on performance of biodegradable jute-fabric/Biopol composites, Composites Science and Technology, Vol. 60, (2000), pp.1115-1124.

(3) Li, X.H., Meng, Y.Z., Wang, S.J., Rajulu, A.V. and Tjong, S.C., Completely biodegradable composites of poly(propylene carbonate) and short, lignocellulose fabric Hildegardia populifolia, Journal of Polymer Science: Part B, Vol. 42, (2004), pp.666-675.

(4) Shibata, M., Takachiyo, K., Ozawa, K., Yosomiya, R. and Takeishi, H., Biodegradable polyester composites reinforced with short abaca fiber, Journal of Applied Polymer Science, Vol. 85, (2002), pp.129-138.

(5) Shibata, M., Ozawa, K., Teramoto, N., Yosomiya, R. and Takeishi, H., Biocomposites made from short abaca fiber and biodegradable polyester, Macromolecular Materials and Engineering, Vol. 288, (2003), pp.35-43. 
(6) Iannace, S., Nocilla, G. and Nicolais, L., Biocomposites based on sea algae fibers and biodegradable thermoplastic matrices, Journal of Applied Polymer Science, Vol. 73, (1999), pp.583-592.

(7) Luo, S. and Netravali A.N., Interfacial and mechanical properties of environment-friendly "green" composites made from pineapple fibers and poly(hydroxybutyrate-co-valerate) resin, Journal of Materials Science, Vol. 34, (1999), pp.3709-3719.

(8) Rout, J., Misra, M., Tripathy, S.S., Nayak, S.K. and Mohanty, A.K., The influence of fibre treatment on the performance of coir-polyester composites, Composites Science and Technology, Vol. 61, (2001), pp.1303-1310.

(9) Bisanda, E.T.N., The effect of alkali treatment on the adhesion characteristics of sisal fibres, Applied Composite Materials, Vol. 7, (2000), pp.331-339.

(10) Gassan, J. and Bledzki, A.K., Possibilities for improving the mechanical properties of jute/epoxy composites by alkali treatment of fibres, Composites Science and Technology, Vol. 59, (1999), pp.1303-1309.

(11) McLaughlin, E.C. and Tait, R.A., Fracture mechanism of plant fibres, Journal of Materials Science, Vol. 15, (1980), pp.89-95.

(12) Zadorecki, PP. and Karnerfors, H., Cellulose fibers as reinforcement in composites: determination of the stiffness of cellulose fibers, Composites Science and Technology, Vol. 27, (1986), pp.291-303.

(13) Myers, G.E. Chahayadi, I.S., Coberly, C.A. and Ermer, D.S., Wood flour/Polypropylene composites: influence of maleated polypropylene and process and composition variables on mechanical properties, International Journal of Polymeric Materials, Vol. 15, (1991), pp.21-44.

(14) Flix, J.M. and Gatenholm, PP., The nature of adhesion in composites of modified cellulose fibers and polypropylene, Journal of Applied Polymer Science, Vol. 42, (1991), pp.609-620.

(15) Mohanty, A.K., Misra, M. and Hinrichsen, G., Biofibers, biodegradable polymers and biocomposites: An overview, Macromolecular Materials and Engineering, Vol. 276/277, (2000), pp.1-24.

(16) Bledzki, A.K. and Gassan, J., Composites reinforced with cellulose based fibres, Progress in Polymer Science, Vol. 24, (1999), pp.221-274.

(17) Saheb, D.N. and Jog, J.P., Natural fiber polymer composites: A review, Advances in Polymer Technology, Vol. 18, (1999), pp.351-363.

(18) Netravali, A.N. and Chabba, S., Composites get greener, Materials Today, Vol. 6(4), (2003), 22-29.

(19) Hermann, A.S., Nickel, J. and Riedel, U., Construction materials based upon biologically renewable resources - from components to finished parts, Polymer Degradation and Stability, Vol. 59, (1998), pp.251-261.

(20) Luo, S. and Netravali, A.N., Mechanical and thermal properties of environment-friendly green composites made from pineapple leaf fibers and poly(hydroxybutyrate-co-valerate) resin, Polymer Composites, Vol. 20, (1999), pp.367-378.

(21) Iji, M., Material Stage, Vol. 45, No.4(2004), pp.90-94. (in Japanese)

(22) Iji, M., Serizawa S. and Inoue K., Development of polylactic acid with kenaf and its application to electronic products, Seikei-Kakou, Vol. 15, No.9(2003), pp.602-604. (in Japanese)

(23) Cao, Y., Shibata, S. and Fukumoto, I., Mechanical properties of biodegradable composites reinforced with bagasse fiber before and after alkali treatments, Composites: Part A, Vol. 37, No.3(2006), pp.423-429.

(24) Cao, Y., Shibata, S. and Fukumoto, I., Fabrication and flexural properties of bagasse fibre reinforced biodegradable composites, Journal of Macromolecular Science: Part B Physics, Vol. 45, No.4(2006), pp.463-474.

(25) Shibata, S., Cao, Y. and Fukumoto, I., The tensile strength of the composites made from 
bagasse fiber and biodegradable resin, Transactions of the Japan Society of Mechanical Engineers, Series C, Vol. 71, No.704(2005), pp.1400-1405. (in Japanese)

(26) Shibata, S., Cao, Y. and Fukumoto, I., The effect of the bagasse fiber on the flexural properties of biodegradable composites, Polymer Composites, Vol. 26, No.5(2005), pp.689-694.

(27) Bodros, E., Pilin, I., Montrelay N. and Baley C., Could biopolymers reinforced by randomly scattered flax fibre be used in structural applications?, Composites Science and Technology, Vol. 67, (2007), pp.462-470.

(28) Takagi, H., Winoto, C.W. and Netravali, A.N., Tensile properties of starch-based "green" composites reinforced with randomly oriented discontinuous MAO fibers, Proceedings of the International Workshop on "Green" Composites, (2002), pp.4-7.

(29) Takagi, H. Press forming of environment-friendly "green" composites reinforced by hemp fibers, Proceedings of the First Taiwan/Japan International Polymer Processing Conference, (2005), pp.44.1-44.4.

(30) Takagi, H. and Ochi, S. Characterization of high-strength "green" composites using Manila hemp fibers and starch-based resin, Proceedings of the Third Japan-Canada Joint Conference on New Applications of Advanced Composites, (2003), pp.19-27.

(31) Gomes, A., Goda, K. and Ohgi, J., Effects of Alkali Treatment to Reinforcement on Tensile Properties of Curaua Fiber Green Composites, JSME International Journal Series A, Vol. 47, No.4(2004), pp.541-546.

(32) Okuno, H. and Takagi, H. Development of "green" composites reinforced by bamboo fibers, In: Proceedings of 3rd International Workshop on Green Composites, Kyoto, Japan, (2005), pp.154-155.

(33) Goda, K., Asai, T. and Yamane, T., Development of ramie fiber reinforced biodegradable resin matrix composites by press forming and effect of chemical treatments, Journal of the Society of Materials Science, Vol. 52, No.10(2003), pp.1245-1252. (in Japanese)

(34) Goda, K., Yamane, T. and Asai, T., Effect of fiber surface treatments on tensile strength of a biodegradable composite reinforced by ramie fibers, Proceedings of 31st FRP Symposium, (2002), pp.297-298. (in Japanese)

(35) Khondker, O.A., Ishiaku, U.S., Nakai, A. and Hamada, H., A novel processing technique for thermoplastic manufacturing of unidirectional composites reinforced with jute fibers, Composites Part A, Vol. 37, (2006), pp.2274-2284.

(36) Chabba, S. and Netravali, A.N., Green Composites Using Modified Soy Protein Concentrate Resin and Flax Fabrics and Yarns, JSME International Journal Series A, Vol. 47, No.4(2004), pp.556-560.

(37) Takagi, H., Ochi, S. and Tanaka, H., Development of high-strength cross-ply "green" composites, Proceedings of 31st FRP Symposium, (2002), pp.301-304. (in Japanese)

(38) Ochi, S., Takagi, H. and Tanaka, H., Tensile properties of Manila hemp fabric reinforced cross-ply "green" composites, Journal of the Society of Materials Science, Vol. 52, (2003), pp.916-921. (in Japanese)

(39) Nakamura, R., Sreekala, M.S., Jouyou, H. and Goda, K., Creation of plasticity in textile green composites using ramie woven fabrics, International Journal of Plastic Technology, Vol. 9, (2005), pp.406-415.

(40) Nakamura, R., Kaji, T., Goda, K., Ohgi, J. and Jouyou H., Development and deformation properties of textile green composites using plain woven fabric of ramie fiber, Proceedings of Third International Workshop on Green Composites, (2005), pp.163-165.

(41) Nakamura, R., Sreekala, M.S., Goda, K., Ohgi, J. and Jouyou H., Plastic deformation behavior of textile green composites using a plain woven ramie fabric, Proceedings of 12th European Conference on Composite Materials, (2006), pp.432.

(42) Nishino, T., Hirano, K., Kotera, M., Nakamae, K. and Inagaki, H., Kenaf reinforced biodegradable composites, Composites Science and Technology, Vol. 63, (2003), 
pp.1281-1286.

(43) Goda, K., Sreekala, M.S., Gomes, A., Kaji, T. and Ohgi, J., Improvement of plant based natural fibers for toughening green composites - Effect of load application during mercerization of ramie fibers, Composites Part A, Vol. 37, (2006), pp.2213-2220.

(44) Hayashi, J., Structural changes of cellulose by mercerization, Cellulose Communication, Vol. 2, (1995), pp.6-12. (in Japanese)

(45) Bledzki, A.K., Fink H.PP. and Specht K., Unidirectional hemp and flax EP- and PP-composites: Influence of defined fiber treatments, Journal of Applied Polymer Science, Vol. 93, (2004), pp.2150-2156.

(46) Uno, T., Suizu, N., Goda, K. and Ohgi, J., Impact properties of mercerized fiber green composites, Proceedings of 6th Global Woods and Natural Fiber Composites Symposium, (2006), B20, pp.1-5.

(47) Turner, J. and Karatzas, C., Advanced spider silk fibers by biomimicry, in natural fibers, plastics and composites, Wallenberger F.T. and Weston N. (Eds.), (2004), Kluwer Academic Publishers, Boston. 